\title{
Pequeña ofrenda cariñosa: Uma carta de Juana de Ibarbourou para Manoelito de Ornellas
}

As relações intercontinentais entre poetas, romancistas, críticos e demais pensadores de países da América Latina no século XX foram marcadas por diferentes momentos de trocas intelectuais que hoje constituem um panorama de diálogos para a história das Artes visuais, da Filosofia e da Literatura latino-americana. O que ainda se mantém de muitas dessas relações entre artistas continua vivo no ambiente dos arquivos e acervos, seja através de presentes, dedicatórias, fotografias ou correspondências.

Esse foi o caso da poetisa uruguaia Juana de Ibarbourou (1892 - 1979) e do intelectual brasileiro Manoelito de Ornellas (1903 - 1969), cuja amizade hoje permanece testemunhada através das correspondências que Juana enviou ao amigo durante os anos de 1949 e 1957. Juana de Ibarbourou, também conhecida no mundo das letras hispânicas como Juana de América, foi uma poetisa uruguaia nascida na cidade de Mello. Foi um dos grandes nomes da poesia uruguaia, e da poesia em língua castelhana, do século XX, tendo sido reconhecida internacionalmente por suas obras, como Las lenguas de diamante (1919) e Raíz Salvaje (1922). Manoelito de Ornellas, por sua vez, foi um intelectual gaúcho nascido na cidade de Itaquí, na fronteira entre Brasil e Argentina. Dedicou toda a sua vida profissional às letras e ao estudo das relações históricas do Rio Grande do Sul. Destacou-se como o autor do romance histórico Tiaraju (1948) e do estudo Gaúchos e Beduínos - A origem étnica e a formação social do Rio Grande do Sul (1948).

A carta que aqui apresentamos, assim como as demais, encontra-se no Acervo Literário Manoelito de Ornellas (ALMAN), depositado no DELFOS - Espaço de Documentação e Memória Cultural, da PUCRS, onde há, até este momento, sete correspondências enviadas ao historiador pela poetisa, e nenhuma evidência de cópias ou rascunhos das correspondências enviadas por Manoelito à sua amiga, o que torna os vestígios dessa amizade estritamente direcionados pelas percepções íntimas de Ibarbourou ${ }^{2}$.

Enviada no dia 31 de Janeiro de 1957, a carta que segue permite que nos inteiremos sobre um fragmento da relação de amizade entre Ibarbourou e Manoelito. O conteúdo da correspondência trata de assuntos cotidianos, desencadeados pela motivação de Juana em desejar votos de ano novo a Manoelito e sua família antes da virada daquele mês de janeiro. A partir das confidencias da poetisa, percebemos os vínculos de amizade e carinho da uruguaia também com a mulher e a filha do intelectual (Lucy e Lilia), manifestadas pela curiosidade da poeta pela escrita da menina, ademais dos diversos elogios; também um envio de poemas novos por parte de Juana eufemisticamente tratados por ela como "pequena ofrenda cariñosa"; detalhes da vida da própria remetente -

\footnotetext{
${ }^{1}$ Mestre em Teoria da Literatura pela Pontifícia Universidade Católica do Rio Grande do Sul (PUCRS). Contato: rg.matheus@gmail.com

${ }^{2}$ Em 2019, as professoras Maria Eunice Moreira e Regina Kohlrausch, da PUCRS, publicaram o artigo intitulado "Juana de Ibarbourou e Manoelito de Ornellas: Bastidores de uma amizade”, no qual tratam mais profundamente das relações entre os dois intelectuais a partir das sete correspondências citadas. O artigo está publicado no volume "Identidades em Diálogo: A mulher na literatura hispano-americana de autoria feminina" (Libretos, 2018).
} 
sua "temporada de buena salud" e suas leituras brasileiras -, além dos últimos acontecimentos daquele novo ano de 1957 - a morte da poeta chilena Gabriela Mistral e uma crise econômica no Uruguay.

$$
\begin{aligned}
& \text { MoR col } 0760 \text { 5. } 1785
\end{aligned}
$$

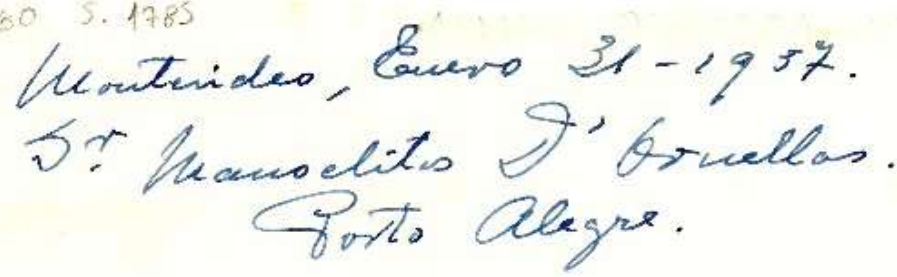

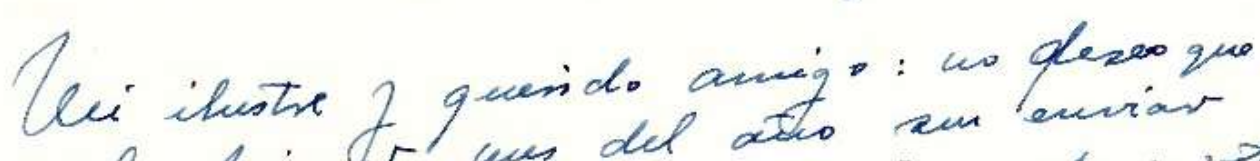

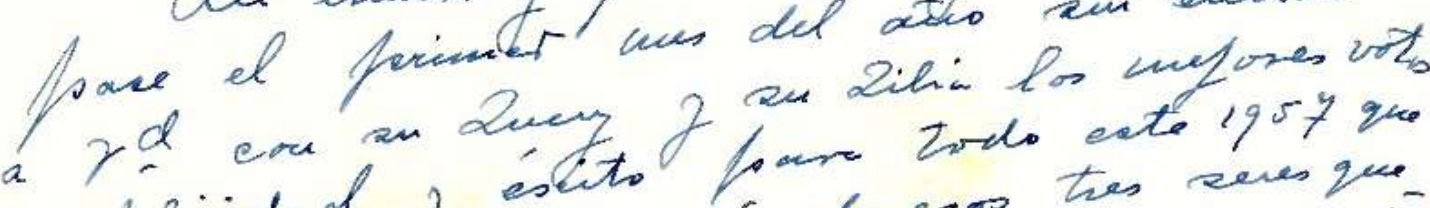

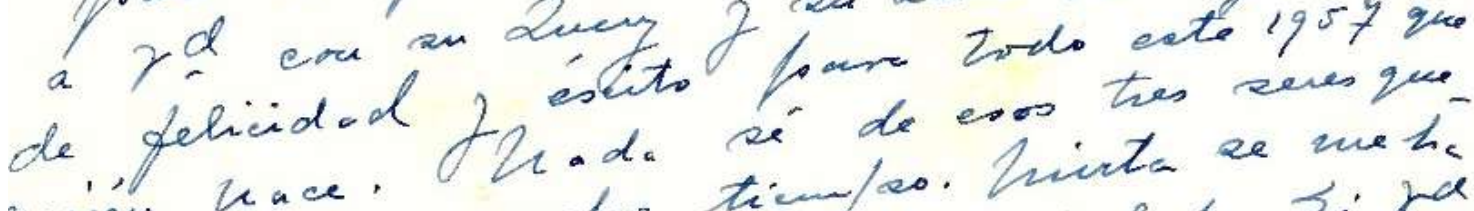
recien Uace. mastwo tiem/so. Hivta ae netic

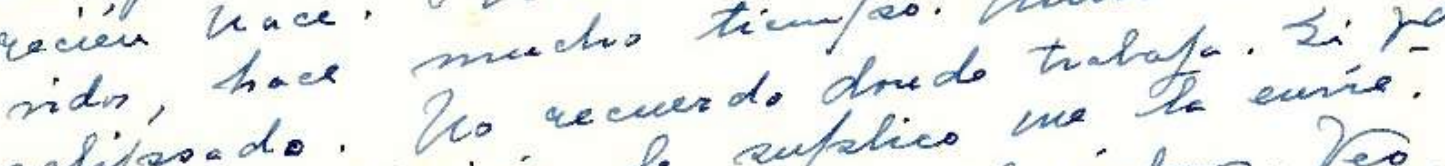

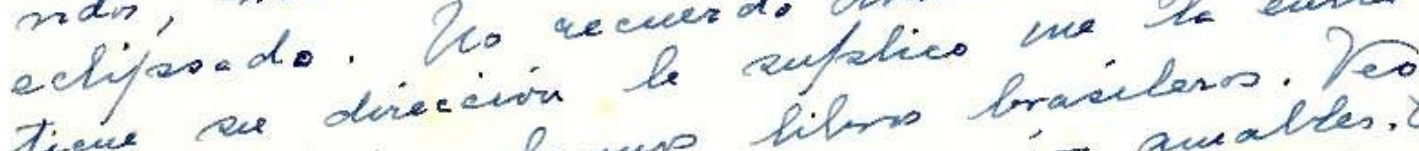

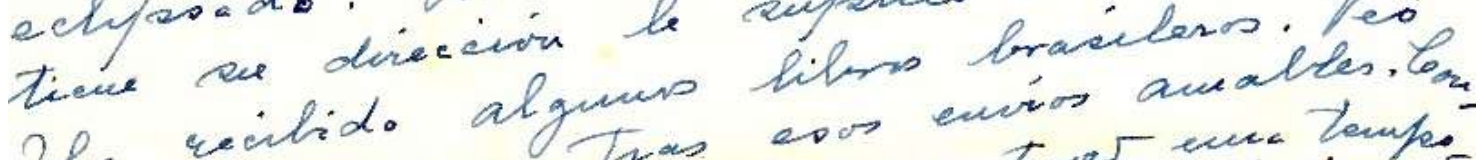

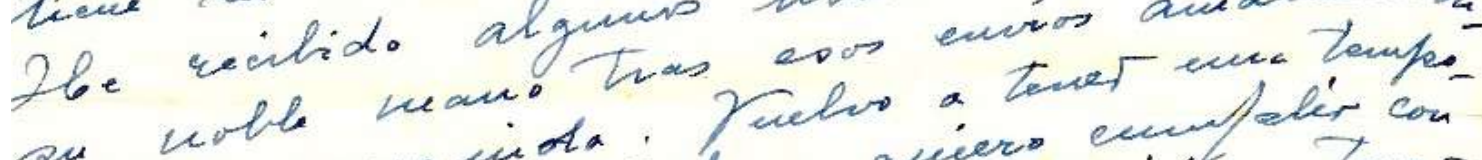

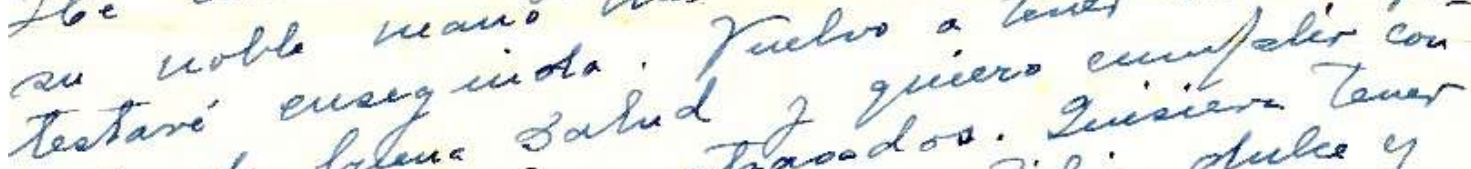

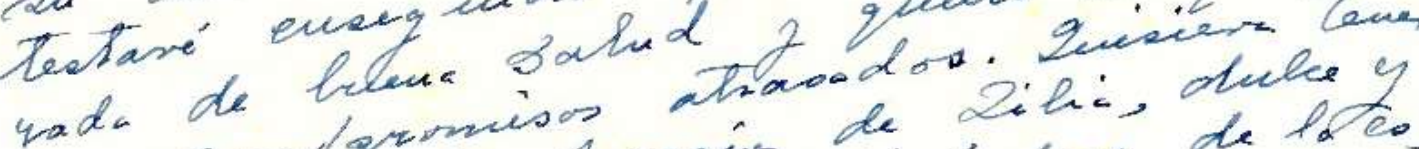

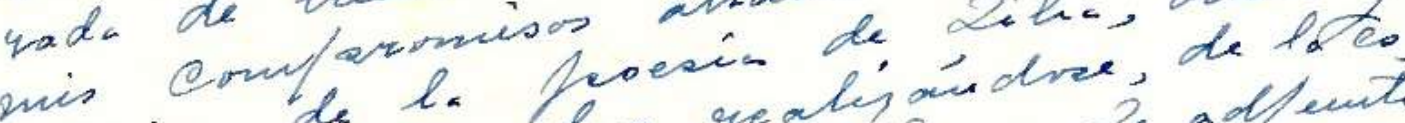

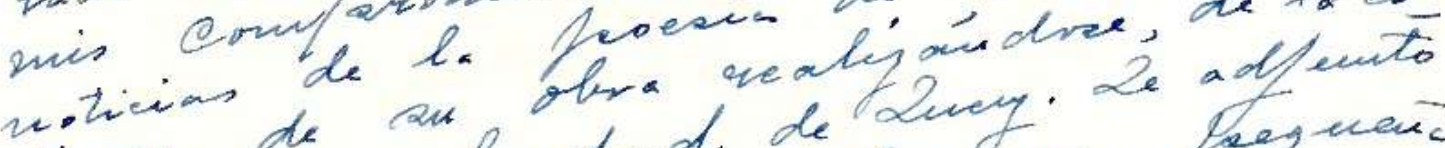

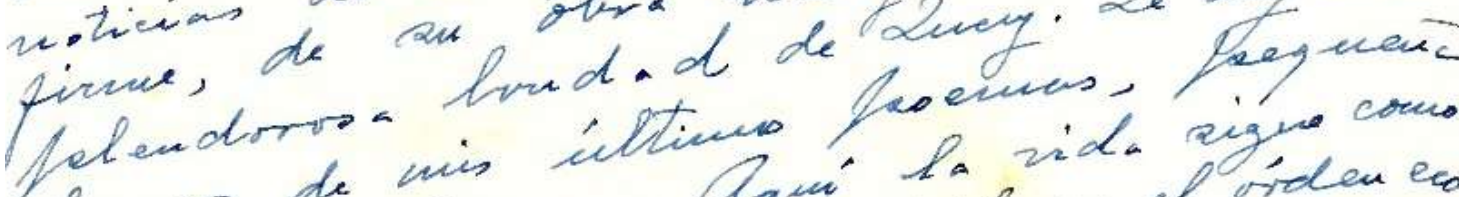

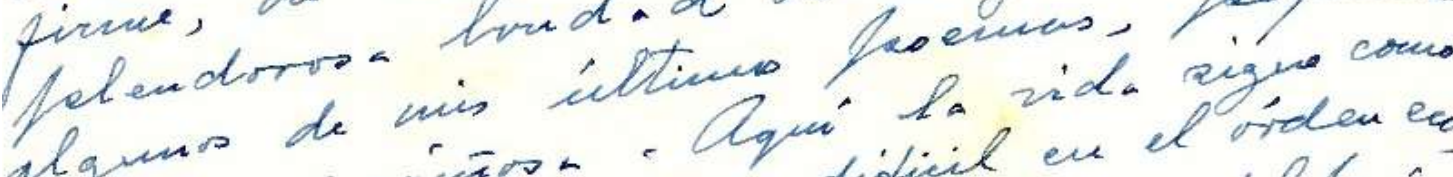

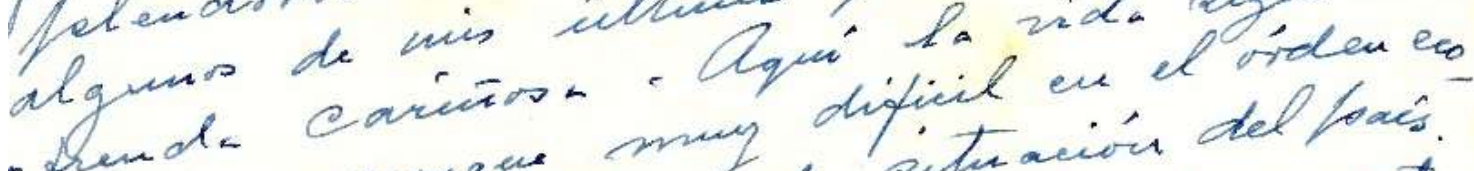

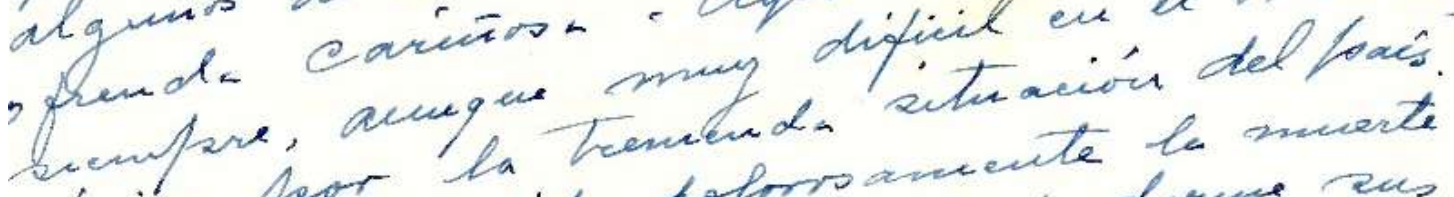

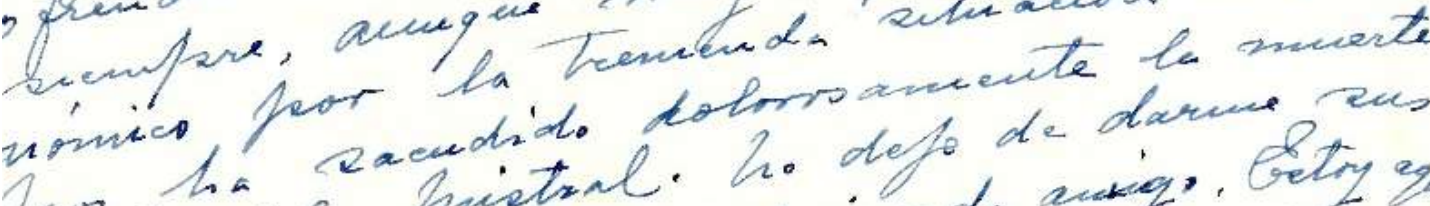

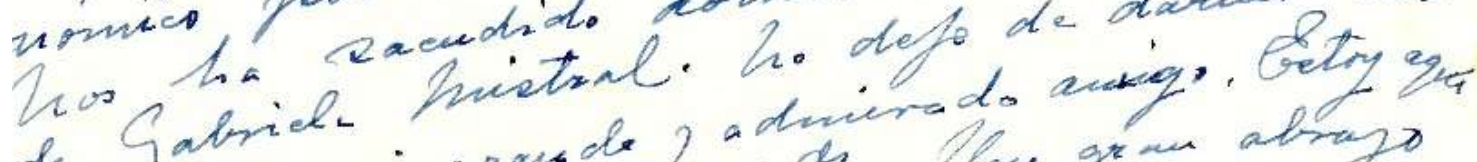

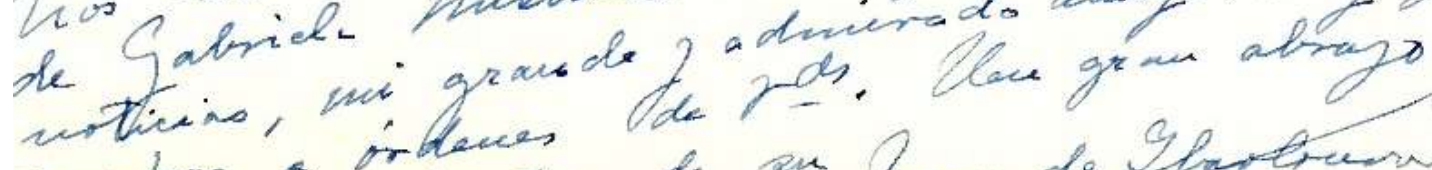

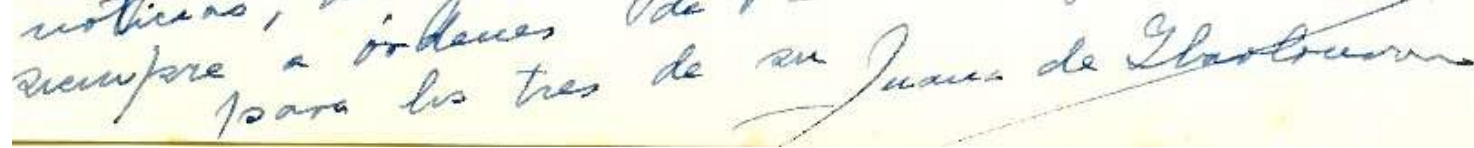
Figura 1 - Carta de Juana de Ibarbourou a Manoelito de Ornellas. Fonte: DELFOS (2019) 
Montevideo, Enero 31-1957.

Sr. Manoelito D'Ornellas.

Porto Alegre.

Mi ilustre y querido amigo: no deseo que pase el primer mes del año sin enviar a Vd. [para] su Lucy y su Lilia los mejores votos de felicidad y éxito para todo este 1957 que recién nace. Nada sé de eses tres seres queridos hace mucho tiempo. Mirta se me ha eclipsado. No recuerdo donde trabaja. Si Vd. tiene su dirección le suplico me la envíe. He recibido algunos libros brasileños. Veo su noble nombre tras esos envíos amables. Contestaré enseguida. Vuelvo a tener una temporada de buena salud y quiero cumplir con mis compromisos atrasados. Quisiera tener noticias de la poesía de Lilia, dulce y firme, de su obra realizándose, de la esplendorosa bondad de Lucy. De adjunto algunos de mis últimos poemas, pequeña ofrenda cariñosa. Aqú la vida sigue como siempre, aunque muy dificil en el orden económico por la tremenda situación del país. Nos ha sacudido dolorosamente la muerte de Gabriela Mistral. No deje de darme sus noticias, mi grande y admirado amigo. Estoy aqui siempre a órdenes de Vds. Un gran abrazo para los tres de su Juana de Ibarbourou. 


\section{Referências}

DELFOS - Espaço de Documentação e Memória Cultural

IBARBOUROU, Juana de. [Correspondência]. Destinatário: Manoelito de Ornellas. Montevideo, 31 jan. 1957. 1 carta.

Recebido em:01 de abril de 2021

Aceito em: 11 de maio de 2021 